\title{
Severe sepsis with Hafnia alvei and dual pulmonary infection with Mycobacterium tuberculosis and Pneumocystis carinii in a late presenter patient infected with HIV - case presentation
}

\author{
Andreea Ardeleanu ${ }^{1 *}$, Ovidiu Roşca ${ }^{2}$, Monica Cialma², Daniela Desagă', Ingrid Deak ${ }^{3}$ \\ From The 7th Romanian National HIV/AIDS Congress and The 2nd Central European HIV Forum \\ Sibiu, Romania. 29-31 May 2014
}

Once thought to be a simple commensal of the gastrointestinal tract, there is increasing evidence to suggest Hafnia alvei is a rare, but significant bacterium that may contribute to opportunistic infections in humans. Bacteremia and respiratory tract infections are the leading extraintestinal manifestations of Hafnia alvei as a pathogen. It can cause disease in immunocompromised patients and it is regularly resistant to multiple drugs.

Patients with HIV may present with both TB and PCP and in these patients, TB seems to account for the most serious symptoms of their disease that require hospitalization.

We report the case of a 36-years old patient admitted in our department in 23 October 2013, for persistent fever, headache, oral candidiasis, productive cough, weight loss and severe asthenia. He tested positive for HIV with a CD4 of 7 cells/ $\mu \mathrm{L}$ and a viral load of 930,795 copies/mL. In the blood culture we isolated Hafnia alvei and the chest CT scan showed "a ground-glass aspect" suggestive for a Pneumocystis carinii pneumonia (PCP). The pneumological evaluation established the imagistic diagnostic of miliary tuberculosis and recommended treatment with tuberculostatic drugs and antibiotic.

Severe sepsis has emerged as a common cause of hospital admission for those living with HIV/AIDS. Sepsis patients had significantly higher in-hospital mortality than did nonsepsis patients. Clinicians should be aware

${ }^{1}$ Department of Infectious Diseases I, Dr. Victor Babeș Clinical Hospital of Infectious Diseases and Pneumology, Timişoara, Romania

Full list of author information is available at the end of the article that patients with HIV/AIDS may present with concurrent pulmonary $\mathrm{TB}$ and $\mathrm{PCP}$, especially in regions that are hyperendemic for TB.

\section{Authors' details}

'Department of Infectious Diseases I, Dr. Victor Babes Clinical Hospital of Infectious Diseases and Pneumology, Timişoara, Romania. ${ }^{2}$ Department of Infectious Diseases I, Victor Babeş University of Medicine and Pharmacy, Timişoara, Romania. ${ }^{3}$ City Hospital Vulcan, Hunedoara, Romania.

Published: 29 May 2014

doi:10.1186/1471-2334-14-S4-P21

Cite this article as: Ardeleanu et al:: Severe sepsis with Hafnia alvei and dual pulmonary infection with Mycobacterium tuberculosis and

Pneumocystis carinii in a late presenter patient infected with HIV - case presentation. BMC Infectious Diseases 2014 14(Suppl 4):P21.

Submit your next manuscript to BioMed Central and take full advantage of:

- Convenient online submission

- Thorough peer review

- No space constraints or color figure charges

- Immediate publication on acceptance

- Inclusion in PubMed, CAS, Scopus and Google Scholar

- Research which is freely available for redistribution 